\title{
Alterações clínicas em crianças após infecção pelo Zika vírus
}

\author{
Clinical changes in children after Zika vírus infection
}

Alteraciones clínicas en niños después de la infección por el Zika vírus

Léia Rodrigues dos Santos Souza ${ }^{1}$, Joselicia Vânia Pereira Alves dos Santos ${ }^{1}$, Cássia do Nascimento Anthelante ${ }^{1}$, Erick Leal Santos Dias ${ }^{1}$, Josely Bruce dos Santos ${ }^{2 *}$.

\section{RESUMO}

Objetivo: Identificar alterações clínicas em crianças após infecção pelo Zika vírus conforme literatura. Métodos: Revisão integrativa da literatura, realizada na base de dados da FIOCRUZ e Biblioteca Virtual em Saúde (BVS) Sistema Latino Americano e do Caribe de informação em Ciências da Saúde (LILACS), Banco de dados de Enfermagem (BDENF) e Medical Literature Analysisand Retrieval System Online (MedLine). Resultados: Foram identificados 8 trabalhos revelando a ocorrência dos nascimentos de crianças com microcefalia, descrevendo alterações no sistema nervoso central e periférico, além das oftálmicas. Conclusão: A pesquisa nos permitiu identificar as consequências que o Zika vírus pode causar para as crianças além de reforçar a relevância da enfermagem nos cuidados a gestante, parturiente e no acompanhamento do crescimento e desenvolvimento dessas crianças e que novos estudos científicos possam contribuir com o desenvolvimento de novas ferramentas para o controle da proliferação do mosquito transmissor (Aedes Aegypti) do Zika Vírus.

Palavras-chave: Zika vírus, Microcefalia, Criança.

\begin{abstract}
Objetivo: To identify clinical alterations in children after infection by Zika vírus according to literature. Methods: Integrative literature review, carried out in the FIOCRUZ database and the Virtual Health Library (VHL) Latin American and Caribbean Health Sciences Information System (LILACS), Nursing Database (BDENF) and Medical Literature Analysisand Retrieval System Online (MedLine). Results: Eight studies revealed the occurrence of the births of children with microcephaly, describing alterations in the central and peripheral nervous system, besides the ophthalmic ones. Conclusion: The research allowed us to identify the devastating consequences the Zika vírus can cause for children in addition to reinforcing the relevance of nursing care in pregnant and parturient women and in monitoring the growth and development of these children and that new scientific studies can contribute to the development of new tools to control the proliferation of the transmitting mosquito (Aedes Aegypti) of Zika vírus.
\end{abstract}

Key words: Zika vírus, Microcephaly, Child.

\section{RESUMEN}

Objetivo: Identificar alteraciones clínicas en niños después de la infección por el Zika vírus según literatura. Métodos: (BVS) Sistema Latinoamericano y del Caribe de información en Ciencias de la Salud (LILACS), Banco de datos de Enfermería (BDENF) y Medical Literature Analysisand Retrieval System (BDENF) y la Biblioteca Virtual en Salud (BVS) Online (MedLine). Resultados: Se identificaron 8 trabajos revelando la

${ }^{1}$ Discente do curso de Enfermagem pelo Centro Universitário Jorge Amado (UNIJORGE) Salvador - BA.

${ }^{2}$ Docente do curso de Enfermagem do Centro Universitário Jorge Amado (UNIJORGE) Salvador - BA.

*E-mail: joselybruce3@gmail.com

SUBMETIDO EM: 10/2018 
ocurrencia de los nacimientos de niños con microcefalia, describiendo alteraciones en el sistema nervioso central y periférico, además de las oftálmicas. Conclusión: La investigación nos permitió identificar las consecuencias devastadoras el Zika vírus puede causar a los niños además de reforzar la relevancia de la enfermería en los cuidados a gestante, parturienta y en el acompañamiento del crecimiento y desarrollo de esos niños y que nuevos estudios científicos puedan contribuir con el desarrollo de nuevas herramientas para el control de la proliferación del mosquito transmisor (Aedes Aegypti) de Zika vírus.

Palabras clave: Zika vírus, Microcefalia, Niño.

\section{INTRODUÇÃO}

A síndrome congênita do Zika vírus são manifestações apresentadas por crianças cujas as mães foram infectadas pelo vírus Zika durante a gestação. Além de microcefalia as crianças apresentam graves danos neurológicos, oftálmicos, auditivos e deformidades crânio facial (FRANÇA G, et al, 2018). São 2.756 casos confirmados entre 2015 a 2018 em todo Brasil de recém-nascidos e crianças com alteração no crescimento e desenvolvimento relacionados a infecção por Zika vírus. Desses 1.820 casos na região Nordeste, 215 na região Centro-Oeste, 515 no Sudeste, 151 na região Norte, 55 na região Sul.

Dentre as manifestações visíveis ao nascer, está a microcefalia, que é uma malformação congênita em que o perímetro cefálico $(\mathrm{PC})$ é abaixo do esperado para o sexo e idade gestacional, podendo trazer consigo retardo mental, cognitivo, motor ou múltiplas deficiências. As mães que tiverem bebês com esta a má formação residiam em áreas com casos de Zika vírus e relataram ter apresentado no primeiro trimestre da gestação exantemas ou rash cutâneo, que são erupções na pele geralmente causados por infecções virais. (VARGAS A, et al. 2016).

O Zika vírus é um arbovírus do gênero flavivírus, a transmissão desta arbovirose se dá principalmente através do vetor o mosquito Aedes Aegypti segundo o ministério da saúde (MS) a proliferação do mosquito se dá pelas condições precárias de sanitarismo urbano disseminando assim várias doenças como dengue, chikunguha, e agora o Zika vírus. Além do mosquito os estudos comprovam que o Zika também é transmitido pela via placentária e pelo sexo (OMS, 2016).

Os sinais e sintomas da infecção acometem somente $18 \%$ dos humanos infectados e tem como manifestações importantes: exantema maculopapular, febre baixa, artralgia, mialgia, dor de cabeça e hiperemia conjuntival não purulenta e sem prurido, edema, dor de garganta, tosse, vômitos e hematospermia. Após três a sete dias, estas manifestações clínicas regridem (BRASIL, 2015). É uma doença de notificação compulsória e está presente na Lista Nacional de Notificação Compulsória de Doenças, Agravos e Eventos de Saúde Pública, e foi acrescentada a essa lista pela Portaria ํㅡ 204, de 17 de fevereiro de 2016, do MS (MUSSO D et al, 2015).

A possível relação entre a ocorrência de microcefalia em recém-nascidos (RN) - perímetro cefálico igual ou inferior a $32 \mathrm{~cm}$ - e a infecção da gestante pelo vírus Zika teve início no Brasil. A partir deste questionamento foram analisados os primeiros 35 casos de microcefalia notificados em oito estados do país no período de agosto e outubro de 2015 , sendo observado que as mães visitaram ou moravam em regiões endêmicas. Desta amostra $71 \%$ dos RN tiveram microcefalia severa (PC com mais de três desvios padrões abaixo da média para a idade e sexo), 49\% apresentaram alterações neurológicas e na realização de exames de neuroimagem todos os $27 \mathrm{RN}$ examinados apresentaram anormalidades. Nestes casos, não houve correlação com outros agentes infecciosos (sífilis, toxoplasmose, rubéola, citomegalovírus e herpes simples) ou perfil genético familiar alterado (SCHULER et al. 2015).

Segundo SALGE A et al (2016), o Brasil foi o primeiro país a relacionar os casos do Zika vírus com as gestantes e o nascimento de bebês com microcefalias. Amostras de quatro gestantes foram testadas e comprovada a infecção por Zika vírus. Destas duas, apresentaram aborto e duas morreram logo após o nascimento. Amostras cerebrais detectaram presença do vírus. Exames como tomografia computadorizada e 
ultrassom transfontanela comprovam alterações como calcificação no cérebro em regiões periventricular, parenquimal, talâmica e na ganglia basal, tais alterações podem trazer sérios danos ao desenvolvimento infantil.

Em 2017, foram registrados 17.594 casos prováveis de Zika vírus no país, já em 2016, no mesmo período, 216.207 casos. Até junho deste ano, foram registrados 4.571 casos. A região Sudeste apresentou o maior número 1.491, na sequência aparece a região Nordeste com 1.187 casos, Centro-Oeste 1.153, Norte 709, e Sul com 31 casos. Em 2017, houve a confirmação de 1 óbito em Rondônia e neste ano mais um óbito no estado da Paraíba. Além disso, 869 casos de gestantes com Zika vírus em todo país, desses 869 , foram confirmados por critérios clínicos laboratoriais e epidemiológicos 330 casos (BRASIL, 2018).

No início do surto em 2015, foram notificados 4119 casos suspeitos de alteração no desenvolvimento infantil relacionado ao Zika vírus. 8604 em 2016, 2645 em 2017e 660 em 2018, num total de 16.028 casos suspeitos. Os casos confirmados somam 1.714, são crianças acompanhadas em puericultura e recebem estimulação precoce em serviços especializados. A concentração dos casos $59,7 \%$ no Nordeste, $24,5 \%$ no Sudeste e Centro-Oeste 7,3\%. Os estados com maior número de crianças com síndrome congênita do zíka vírus são Pernambuco, Bahia, São Paulo, Paraíba e Rio de Janeiro (BRASIL, 2018).

O surto tem mobilizado muitos pediatras, assim como equipes de enfermagem voluntariamente, visando à diminuição de mortalidade das complicações Zika vírus, além de ofertar assistência de qualidade buscando a promoção de saúde, é necessário o acompanhamento com exames sorológicos da mãe e neonato com exames de imagens (tomografia computadorizada, ressonância magnética e ultrassonografia transfontanelar).Os acompanhamentos devem ser feitos com infectologistas, neurologistas, oftalmologistas pediátricos, talvez sendo necessários outros profissionais para maior diagnóstico e seguimento quanto ao desenvolvimento da criança (REIS, 2015).

Visto todas essas ocorrências a microcefalia tem se tornado um agravo de grande importância emergencial na saúde pública do País, por atingir a qualidade de vida de milhares de famílias, assim como tem causado grande impacto na vida de crianças e aumentando o índice de mortalidade infantil (BRASIL, 2015).

Palácios e Rego (2016), relatam que ainda são desconhecidos as inúmeras alterações neurológicas e os impactos que a síndrome do Zika vírus pode trazer ao desenvolvimento das crianças atingidas e as famílias. Desta forma, o objetivo deste estudo é identificar as alterações clínicas em crianças após infecção pelo Zika vírus na literatura científica.

\section{METODOLOGIA}

Trata-se de uma revisão integrativa da literatura, de abordagem qualitativa, descritiva e exploratória. As etapas do processo de elaboração da revisão integrativa, foram: elaboração da pergunta norteadora, estabelecimento dos objetivos da revisão e critérios de inclusão e exclusão dos artigos; definição das informações a serem extraídas das pesquisas; seleção dos artigos na literatura; análise dos resultados; discussão dos achados e apresentação da revisão (SOUZA S, et al. 2010).

A busca dos estudos ocorreu no período de agosto a setembro de 2018 na base de dados da FIOCRUZ e Biblioteca Virtual em Saúde (BVS)Sistema Latino Americano e do Caribe de informação em Ciências da Saúde (LILACS), Banco de dados de Enfermagem (BDENF) e Medical Literature Analysisand Retrieval System Online (MedLine). Os descritores utilizados foram: "Zika vírus; Microcefalia; Criança;", unidos pelo modelador boleando AND. Utilizou-se como critério de inclusão artigos contemplando os descritores acima mencionados, disponíveis na íntegra de forma gratuita, publicados nos anos de 2015 a 2018 e no idioma português, inglês e espanhol.

Foram excluídos artigos de revisão e demais estudos que, após leitura de título, resumos e texto completo encontravam-se duplicados não tinham pertinência para responder à questão proposta para esta revisão integrativa. 
A presente pesquisa contemplou apenas dados disponibilizados pela plataforma de acesso a dados públicos do MS, nos quais não há identificação de indivíduos, tornando-se dispensável a apreciação e a aprovação de um Comitê de Ética em Pesquisa, obedecendo à lei número 9.610, de 19 de fevereiro de 1998, que regulamenta os direitos autorais. Dessa forma, todos os autores citados estão devidamente referenciados.

\section{RESULTADOS}

Foram encontrados 187 artigos, após a seleção de artigos publicados entre os anos de 2015 a 2018 , disponíveis na íntegra, nos idiomas inglês, português e espanhol, ficaram um total de 154, foram excluídos 28 por estarem duplicados, 118 indisponíveis que não atendiam a temática pesquisada. Após a leitura dos resumos apenas 8 trabalhos se relacionaram ao tema em estudo, em que 4 encontrados na MEDLINE, 1 na LILACS, 1 na BDENF, 1 na FIOCRUZ e 1 na SCIELO. Quanto ao país de origem dos estudos, todos foram realizados no Brasil, provavelmente pela epidemia do Zika vírus ter ocorrido neste país no ano de 2015 e como consequência a ocorrência dos nascimentos de crianças com microcefalia. Em relação ao periódico de publicação, quatro foram publicados em revistas internacionais com ampla temática e alto fator de impacto, dois em revistas específicas de oftalmologia, um em enfermagem e outro em neurologia, sendo estes últimos quatro, em revistas brasileiras. Quanto ao tipo de estudo é uma Revisão Integrativa e Crítica da Literatura, Quantitativo Analítico, Relato de Caso, Estudo de Coorte e Análise retrospectiva.

Dentre as repercussões encontradas através dos estudos, estão as relacionadas ao sistema nervoso central e periférico, além das oftálmicas. Os resultados estão apresentados sob forma de quadro sintético.

\section{DISCUSSÃO}

Os achados oftálmicos incluem alterações como nistagmo horizontal, estrabismo, hipoplasia em nervo óptico com anel duplo placa e palidez, manchas e alterações de fundo na região macular, perda de reflexo foveal, miopia, hipermetropia (VENTURA C, et al,2016; FILHO J, et al, 2018; SALGE A, et al (2016).

A atrofia neuroretinal macular, mancha macular de pigmento bruto, perda de reflexo foveal, alterações do fundo na região macular, miopia com hipermetropia foram identificados nos exames oculares dos neonatos infectados pelo vírus, sendo a mais comum nesse período a hipoplasia do nervo óptico (SALGE A, et al (2016), EICKMANN S et al, 2016;). A mácula é uma pequena área da retina em que acuidade visual apresenta maior nitidez. A mácula transmite ao cérebro $90 \%$ da informação visual. A mácula pode ser lesada por processos inflamatórios, a visão torna-se embaçada e uma mancha escura cobrindo o centro da visão, as imagens podem parecer embaçadas ou amareladas; diminuição da percepção visual; perspicácia de linhas retas como desfiguradas ou onduladas; mancha sombreada central e a falta de detecção de flashes de luz também são descritas (QUEIROZ J, et al. 2010).

Um achado aparente ao nascer e que pode acarretar em deformidades oftálmicas é a microcefalia, esta condição pode levar a paralisia cerebral que como consequências atrofia macular e alteração na retina no nervo ótico. A paralisia cerebral pode ser causada por infecção no período intra-uterino acarretando incapacidades físicas na infância como alterações a nível sensorial, ocasionando anomalias na visão. a acuidade visual pode ser comprometida ou de forma normal, podendo surgir complicações como seroso da retina em uma porcentagem de 30\% e raramente neovascularização de coroide (EICKMANN S, et al 2016; COLAÇO M, et al. 2014; MARTINS T et al. 2015).

A infecção pelo Zika vírus tem relação direta com a redução do parênquima cerebral principalmente quando há infecção das células progenitoras neuronais corticais. Isso se dá, pois, o Zika vírus é neurotrópico, ocasionando diminuição do crescimento celular, morte por vias de apoptose e autofagia neuronal, com consequente afilamento do córtex (RIBEIRO B et al, 2017). 
Quadro 1 - Caracterização dos artigos da revisão integrativa. Salvador, Brasil, 2018.

\begin{tabular}{|c|c|c|c|c|c|}
\hline ID & Autor & Ano/País & Periódico & Tipo de Estudo & Resultado do Estudo \\
\hline 01 & $\begin{array}{l}\text { Ventura } \\
\mathrm{CV} \text {, et al }\end{array}$ & 2016; Brasil & $\begin{array}{l}\text { Arquivos } \\
\text { Brasileiros } \\
\text { Oftalmologia }\end{array}$ & $\begin{array}{l}\text { Quantitativo } \\
\text { analítico }\end{array}$ & $\begin{array}{l}\text { Foi observado Nistagmo horizontal em um lactente. Estrabismo em } 6 \text { pacientes. } \\
\text { Avaliação da retina revelou alterações do nervo óptico e macular em } 17 \text { olhos. Os } \\
\text { achados do nervo óptico consistiram em hipoplasia com o anel duplo placa e } \\
\text { palidez. }\end{array}$ \\
\hline 02 & $\begin{array}{c}\text { Salge AKM, } \\
\text { et al }\end{array}$ & 2016; Brasil & $\begin{array}{c}\text { Revista Eletrônica } \\
\text { de Enfermagem }\end{array}$ & $\begin{array}{c}\text { Revisão } \\
\text { integrativa }\end{array}$ & $\begin{array}{c}\text { As três crianças tinham mancha macular de pigmento bruto e perda de reflexo } \\
\text { foveal, alteraçôes do fundo na região macular e calcificações cerebrais detectadas } \\
\text { por tomografia computadorizada, quatro apresentavam miopia com hipermetropia } \\
\text { sendo a mais comum nesse período, nove lactentes mostrou hipoplasia do nervo } \\
\text { óptico e palidez. }\end{array}$ \\
\hline 03 & $\begin{array}{l}\text { Campos } \\
\text { AGM; Lira } \\
\text { R PC; } \\
\text { Arantes } \\
\text { TEF }\end{array}$ & 2016; Brasil & $\begin{array}{l}\text { Arquivos } \\
\text { Brasileiros } \\
\text { Oftalmologia }\end{array}$ & Relato de caso & $\begin{array}{l}\text { Aumento dos ventrículos e subdural espaço e focos esparsos de calcificação no } \\
\text { córtex cerebral e periventricular regiões. Atrofia coriorretiniana bem definida na } \\
\text { mácula do olho esquerdo. Atrofia da retina externa, incluindo a camada nuclear } \\
\text { externa e zona elipsoide, associada ao pigmento da retina hiper-reflexividade do } \\
\text { epitélio. }\end{array}$ \\
\hline 04 & $\begin{array}{c}\text { Nunes ML, } \\
\text { et al }\end{array}$ & 2016; Brasil & $\begin{array}{l}\text { Jornal de } \\
\text { Pediatria Porto } \\
\text { Alegre }\end{array}$ & $\begin{array}{l}\text { Revisão crítica de } \\
\text { literatura }\end{array}$ & $\begin{array}{c}\text { Dos } 37 \text { recém nascidos apresentaram calcificações em parênquima cerebrais, } \\
\text { emperiventriculos, anomalias de migração neuronal,anormalidades no } \\
\text { vermiscerebelaredisnesia do corpo caloso. }\end{array}$ \\
\hline 05 & $\begin{array}{c}\text { Filho JO, et } \\
\text { al }\end{array}$ & 2018; EUA & $\begin{array}{l}\text { The American } \\
\text { Journal of } \\
\text { Tropical } \\
\text { MedicineandHygi } \\
\text { ene, New Haven, }\end{array}$ & Estudo de coorte & $\begin{array}{l}\text { Principal desfecho neurológico a epilepsia, que ocorreu em } 48 \% \text { dos lactentes além } \\
\text { disso calcificações e ventriculomegaliacerebrais, graves distúrbios oftalmológicos. } \\
\text { Mortes relacionada a síndrome congênita do zika vírus na primeira infância. }\end{array}$ \\
\hline 06 & $\begin{array}{c}\text { Leal MC, et } \\
\text { al }\end{array}$ & 2016; EUA & $\begin{array}{l}\text { MMWR: Morbidity } \\
\text { and mortality } \\
\text { weekly report }\end{array}$ & $\begin{array}{c}\text { Análise } \\
\text { retrospectiva }\end{array}$ & $\begin{array}{c}\text { Lactentes apresentaram perda auditiva neurossensorial, informações adicionais } \\
\text { são necessárias para entender a prevalência e o espectro de perda auditiva em } \\
\text { crianças com infecção congênita por zika vírus incluindo crianças que parecem } \\
\text { normais ao nascimento. }\end{array}$ \\
\hline 07 & $\begin{array}{c}\text { Linden } \\
\text { VVD, et al }\end{array}$ & 2016; EUA & $\begin{array}{l}\text { MMWR: Morbidity } \\
\text { and mortality } \\
\text { weekly report }\end{array}$ & $\begin{array}{c}\text { Análise } \\
\text { retrospectiva }\end{array}$ & $\begin{array}{l}\text { Analisando-se } 13 \text { crianças que nasceram, em dois estados no Brasil, detectaram - } \\
\text { se anomalias cerebrais na neuroimagemincluindo diminuição do volume cerebral, } \\
\text { ventriculomegalia, calcificações subcorticais e malformações corticais }\end{array}$ \\
\hline 08 & $\begin{array}{c}\text { Marianne } \\
\mathrm{B} \text {, et al }\end{array}$ & 2016; França & Euro Surveillance & $\begin{array}{c}\text { Análise } \\
\text { retrospectiva }\end{array}$ & $\begin{array}{l}\text { De } 2014 \text { a 2015, após a epidemia do ZIKV, observamos um aumento incomum de } \\
\text { malformações congênitas anuais (duas vezes), disfunção do tronco cerebral ( } 31 \\
\text { vezes) e microcefalia grave (14 vezes) entre fetos e recém-nascidos. }\end{array}$ \\
\hline
\end{tabular}

Fonte: Biblioteca Virtual em Saúde, Scielo e Fiocruz. 
Deste modo, o principal achado foram as calcificações cerebrais em regiões como periventrículos e ventriculomegalia (NUNES ML, et al; SALGE A, et al (2016); FILHO J, et al. 2018. As calcificações intracranianas representam um achado comum em várias infecções congênitas, para OLIVEIRA A, et al. (2016) o vírus destrói as células cerebrais, formando cicatrizes que são calcificadas como forma de recuperação, além disso o vírus continua lesando o cérebro mesmo após o nascimento da criança. Estudo com uma criança com nascimento típico, após 6 meses de vida, a Tomografia de crânio mostrou calcificação e atraso no desenvolvimento como hipertonia global e hemiplegia em lado direito (BOTELHO ACG et al, 2016).

Imagens de TC e Ressonância Magnética, mostraram que as calcificações eram localizadas na junção de substâncias branca cortical e sub cortical, além de diminuição do volume do cerebelo e outras alterações neurológicas graves que alteram significativamente o desenvolvimento infantil (ARAGÃO M, et al. 2016). Para ALVES L, et al. (2016), as calcificações e demais alterações neurológicas apresentadas por crianças com síndrome congênita do zika vírus são danos aos neurônios que podem causar atraso de desenvolvimento neurológico.

O sistema nervoso central (SNC) é composto por encéfalo e cérebro e seus ventrículos envoltos por meninges contido no crânio, e a medula espinhal contida na coluna vertebral todas essas estruturas são irrigadas pelo liquido cefalorraquidiano (LCR) (REED CU, 2013). A ventrículomegalia é o excesso do LCR nos ventrículos laterais cerebrais é uma anomalia frequente diagnosticada pela ultrassonografia no período prénatal (RAMOS C, 2016).

O desenvolvimento do SNC humano dá-se na fase embrionária (gastrulação), onde por volta da 14ํㅜㄴ semana do embrião a placa neural é formada, ainda segundo os autores a gravidade das alterações neurológicas depende da fase gestacional em que ocorreu a infecção, nos primeiros trimestres a gravidade das alterações são ainda maiores. Ainda segundo eles as crianças com síndrome congênita do zika vírus (CZS), apresentam ventriculomegalias severas (NUNES ML, et al. 2016).

A ventrículomegalia é oriunda da má drenagem do LCR para a corrente sanguínea, alterando fluxo e pressão, acumulando-se nos ventrículos onde são produzidos. Assim, ocorre injúria ao SNC ainda imaturo, devido à compressão das estruturas contra a caixa craniana. Outro fator é que estes contêm proteínas importantes para a multiplicação dos neurônios corticais, bem como seu crescimento. Desta forma, qualquer variação do LCR pode comprometer o desenvolvimento do SNC (SAQUETTO MB, 2013).

Estas injúrias têm como consequência a paralisia cerebral e afilamento do parênquima cerebral, refletindo na deficiência do controle motor. Observado por BRUNONI (2016); como disfunção do tronco cerebral que implicará na má coordenação entre sucção, deglutição, respiração, espasticidade, contraturas de membros, anomalias no sistema ocular e auditiva, além de distúrbios comportamentais.

Um estudo realizado com 30 crianças positivas para ZKV na região metropolitana de Salvador, Bahia, Brasil, foram encontrados hipotonia axial $86,1 \%$, hipertonia apendicular sem estimulação $80,6 \%$, hipertonia apendicular com estimulação $76,4 \%$. A hiperreflexia $90,3 \%$, irritabilidade $86,1 \%$ e tremores $79,2 \%$. Os reflexos primitivos estavam presentes, porém persistiam para além da idade esperada (SANTOS JB, et al. 2018).

A infecção pelo Zika vírus causa anormalidades cerebrais assim como microcefalia, mas não é conhecida a perda auditiva por infecção congênita por Zika vírus. Assim uma pesquisa realizada com 70 crianças de 0 a 10 meses com evidências laboratoriais por infecção do Zika Vírus apenas 7\% apresentaram alterações auditivas, ambas tinham microcefalia grave. Dessa forma, a perda auditiva estava inclusa a outras infecções congênitas como, por exemplo, citomegalovirus (CMV), rubéola, toxoplasmose, sífilis geram um número maior (LEAL M, et al. 2016). Sabendo que existe um papel fundamental no desenvolvimento infantil, qualquer alteração auditiva poderá trazer consequências sociais e cognitivas, linguísticas, além de ser um fator de risco. Por essas razões, o diagnóstico precoce evitaria comprometimento na audição infantil (BRASIL, 2013). Deste modo a avaliação auditiva, sendo realizada nos primeiros meses de vida permite verificar o desenvolvimento auditivo da criança, podendo identificar a existência de distúrbios ou presença de sinais sugestivos de alteração e processamento auditivo (LUIZ KG, et al. 2015). 


\section{CONCLUSÃO}

Os dados pesquisados sobre as repercussões do Zika vírus em crianças nos permite entender as consequências e a história natural dessa condição. Espera-se que novos estudos científicos possam contribuir para com o controle do mosquito transmissor do Zika vírus. Além de aprofundar as repercussões causadas por ele, visando diminuir as anomalias ocasionadas pelo mosquito transmissor nessas crianças e em suas famílias.

\section{REFERÊNCIAS}

1. ALVES L, CRUZ D, LINDER A, et al. Crises epilépticas em crianças com síndrome congênita do Zika vírus, Recife. Revista Brasileira de Saúde Materno Infantil, 16 (Supl. 1): S33-S37 nov., 2016.

2. ARAGÃO M, LINDEN V, LIMA M et al. Clinical features and neuroimaging (CT and MRI) findingsin presumed Zika virus related congenital infection and microcephaly: retrospective case series study. The bmj, BMJ 2016;353: i1901, doi: 10.1136/bmj.i1901.

3. BESNARD M, EYROLLE-GUIGNOT D, GUILLEMETTE-ARTUR $P$ et al. Congenital cerebral malformations and dysfunction in fetuses and newborns following the 2013 to 2014 Zika virus epidemic in French Polynesia. Euro Surveillance, 2016; 21(13).

4. BOLETIM EPIDEMIOLOGICO, Secretaria de vigilância em saúde, Ministério da Saúde, 2018; 49:40. Disponível em: http://portalms.saude.gov.br/boletins-epidemiologicos. Acesso em 27 de setembro de 2018.

5. Botelho ACG, Neri LV, Silva MQF da, Lima TX de, Santos KG dos, Cunha RMA da et al. Infecção congênita presumível por Zika vírus: achados do desenvolvimento neuropsicomotor - relato de casos. Rev. Bras. Saude Mater. Infant. [Internet]. 2016 Nov [cited 2019 Jan 10] ; 16( Suppl 1 ): 39-44. Available from: http://www.scielo.br/scielo.php?script=sci_arttext\&pid=S151938292016000800004\&ling=en. http://dx.doi.org/10.1590/1806-9304201600s100004.

6. BRASIL. Ministério da saúde, Secretaria de Atenção à Saúde, Departamento de Ações Programáticas Estratégicas, Diretrizes de Atenção a pessoa com Paralisia Cerebral, Brasília, 2013, p. 27. Disponivel em:< http://bvsms.saude.gov.br/bvs/publicacoes/diretrizes atencao paralisia cerebral.pdf $>$. Acesso em 05 de outubro de 2018.

7. CAMPOS A, LIRA R, ARANTES T. Optical coherence tomography of macular atrophy associated with microcephaly and presumed intrauterine Zika virus infection, São Paulo. Arquivos Brasileiros Oftalmologia, 2016;79(6):400-1.

8. COLAÇO M, CARDOSO J, PINTO R et al. O Olho e a Visão em crianças com Paralisia Cerebral - manifestações oftalmológicas a propósito de 16 casos. Revista da Sociedade Portuguesa de Oftalmologia, 2014; 38:71-78.

9. COSTA J, NUNES M, FIORI R. Convulsões no período neonatal. Jornal de Pediatria, 2001; 77: 115-122.

10. EICKMANN S, CARVALHO M, RAMOS R et al. Síndrome da infecção congênita pelo vírus Zika, Rio de Janeiro. Cad. Saúde Pública, 32(7):e00047716, jul, 2016.

11. FACCINI L, RIBEIRO E, FEITOSA I et al. Possível associação entre a infecção pelo vírus zika e a microcefalia, Brasil. Morbidity and Mortality Weekly Report, 2015; 65(3).

12. FILHO, H. Abordagem das Crises Epilépticas nas Emergências Pediátricas, Rio janeiro. Revista de Pediatria SOPERJ, 13, .02, 29-34, dez 2012.

13. FILHO J, FELZEMBURGH R, COSTA F et al. Seizures as a Complication of Congenital Zika Syndrome in Early Infancy American. Journal Tropical Medicine and HygieneNew Haven, 98, 6 .1860-1862.April,2018.

14. FRANÇA G, PEDI V, GARCIA $M$ et al. Síndrome congênita associada a infecção pelo vírus zíka $m$ nascidos no Brasil: Descrição da distribuição dos casos notificados e confirmados em 2015, 2016, Brasilia-DF. Epidemiol serv. Saúde, 2018; 27:2-2017473.

15. LEAL M, MUNIZ L, FERREIRA T et al. Hearing Loss in Infants with Microcephaly and Evidence of Congenital Zika Virus Infection Brazil. United States Department of Health and Human Services, Estados Unidos, 2016; 65:917-19.

16. LINDEN V, PESSOA A, DOBYS W et al. Description of 13 Infants Born During October 2015-January 2016 With Congenital Zika Virus Infection Without Microcephaly at Birth, Brazil. United States Department of Health and Human Services, 2016; 65(47)1343-1348.

17. Luiz KG, SANTOS GI, VIEIRA RD et al. Febre pelo vírus Zika, Brasília. Epidemiologia e Serviços de Saúde, $2015 ; 24: 785-788$. 
18. MARTINS T, MARTINS D, COSTA A et al. Paciente com síndrome de Morning Glory. Einstein. 2015;13(1):1656.

19. MUSSO D, ROCHE C, NHAN T et al. Detection of Zika virus in saliva. Journal of Clinical Virology, 2015; 68:5355.

20. NATHAN G, JASON L, MORITZ K, et al. Genomic epidemiology reveals multiple introductions of Zika virus into the United States. HHS Public Access, 2017; 546:401-20.

21. NUNES ML, CARLINI CR, MARINOWIC D,et al. Microcefalia e Vírus Zika: uma análise clínica e epidemiológica do atual surto no Brasil, Rio de Janeiro, Sociedade Brasileira de Pediatria, 2016; 92(3):230-40.Disponivel em: http://dx.doi.org/10.1016/j.jped.2016.02.009. Acesso em 29 de Setembro de 2018.

22. OLIVEIRA A, MALINGER G, XIMENES R et al. Microcefalia e outras manifestações relacionadas ao vírus Zika: impacto nas crianças, nas famílias e nas equipes de saúde. Physician Alert. 2016; 47:6-7.

23. Organização Pan- Americana da Saúde. Resposta da Representação da OPAS/OMS no Brasil para a epidemia do vírus da Zika e suas consequências. Organização Mundial da Saúde, Brasília, PAG: 1-9. Disponível em: http:// www.paho.org/bra/salazika. Acesso em 30 de Setembro de 2018.

24. Protocolo de Atenção à Saúde e Resposta à Ocorrência de Microcefalia relacionada à infecção pelo vírus zika, Brasília, 2015. Disponível em: http:// www.saude.gov.br/sas. Acesso em 27 de Setembro de 2018.

25. Protocolo de Atenção à Saúde e Resposta à Ocorrência de Microcefalia Relacionada à Infecção pelo Vírus Ziika, Brasília, 2015. Disponível em: http:// www.saude.gov.br/sas. Acesso em 27 de Setembro de 2018.

26. QUEIROZ, J; JUNIOR Q, JOAQUIM Q. Degeneração macular relacionada à idade: considerações histopatológicas, Rio de Janeiro. Revista Brasileira de Oftalmologia, v.69 n.6, p.400-6, Jun./Nov. 2010.

27. REGO S, PALACIOS M. Ética, saúde global e a infecção pelo vírus Zika: uma visão a partir do Brasil. Revista Bioética, 2016; 24:430-4.

28. RAMOS C. Ventriculomegalia Cerebral Fetal Isolada: Correlação do Diâmetro do com Átrio com Prognostico pós natal.2006. Dissertação (mestrado em ciências, área de concentração obstetrícia e ginecologia) - Faculdade de Medicina da Universidade de São Paulo, São Paulo, 2006;97p.

29. REED C U. Neurologia: noções básicas sobre a especialidade Departamento de Neurologia da Faculdade de Medicina da USP. Disponível em:http://medicina.fm.usp.br/pdf/neurologia.pdf 2013. Acesso em 30 de Setembro de 2018.

30. RIBEIRO B, MUNIZ B, GASPARETTO E et al. Síndrome congênita pelo vírus Zika e achados de neuroimagem: o que sabemos até o momento? Radiologia Brasileira. 2017;50(5).

31. FILHO J, FELZEMBURGH R, COSTA F et al. Zika vírus infectionduringpregnancyand microcephaly in newborns: na integrativeliteraturereview, Goiás. Revista Eletrônica de Enfermagem,2016; 18:e1137.

32. SANTOS JB, LIMA CC, ALMEIDA AO et al. Perfil sociodemográfico e clínico de nascidos com microcefalia. Dissertação (Mestrando em enfermagem pelo programa de pós-graduação em enfermagem) - Universidade Federal da Bahia, Salvador, 2018; 13 p.

33. SAQUETTO MB. Repercussões clínicas e motoras em crianças com hidrocefalia submetidas ao tratamento cirúrgico. 2013. Dissertação (Mestrado Programa de Pós-Graduação em Enfermagem e Saúde) - Universidade Estadual do Sudoeste da Bahia - UESB, Jequié, 2013; 63 p.

34. SOUZA S, DIAS M, CARVALHO R. Revisão integrativa: o que é e como fazer. Einstein, Morumbi, v. 8, n. 1, p. 102-106, 2010.

35. SOUZA A, SOUZA A, FAQUIN S et al. Alterações ultrassonográficas intraútero, crescimento da circunferência cefálica fetal e desfechos neonatais entre casos presumíveis de síndrome da Zika congênita no Brasil. Revista Brasileira de Saúde Materno Infantil, 2016; 16 (Supl. 1): 17-25.

36. VARGAS A; SAAD E; DIMECH G et al. Características dos primeiros casos de microcefalia possivelmente relacionados ao vírus Zika notificados na Região Metropolitana de Recife, Pernambuco, Brasilia. Epidemiologia e Serviço de Saúde 2016, 25(4):691-700.

37. VENTURA C, MAIA M, VENTURA B et al. Ophthalmological findings in infants with microcephaly and presumable intra-uterus Zika virus infection. Arquivo Brasileiros Oftalmologia, 2016; 79(1):1-3. 